UCRL-ID- 133334

\title{
Final Report on LDRD Project "Proliferation-Resistant Fuel Cycles"
}

Neil W. Brown

James A. Hassberger

February 25, 1999

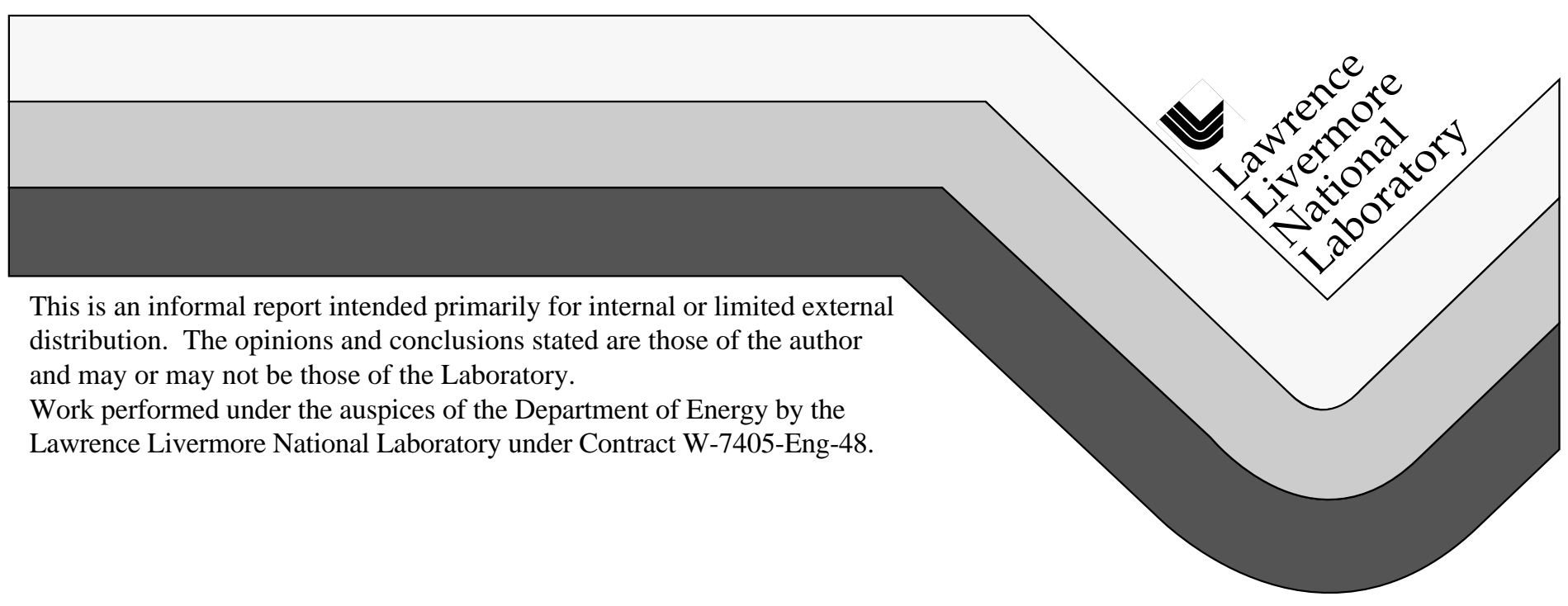




\section{DISCLAIMER}

This document was prepared as an account of work sponsored by an agency of the United States Government. Neither the United States Government nor the University of California nor any of their employees, makes any warranty, express or implied, or assumes any legal liability or responsibility for the accuracy, completeness, or usefulness of any information, apparatus, product, or process disclosed, or represents that its use would not infringe privately owned rights. Reference herein to any specific commercial product, process, or service by trade name, trademark, manufacturer, or otherwise, does not necessarily constitute or imply its endorsement, recommendation, or favoring by the United States Government or the University of California. The views and opinions of authors expressed herein do not necessarily state or reflect those of the United States Government or the University of California, and shall not be used for advertising or product endorsement purposes.

This report has been reproduced directly from the best available copy.

Available to DOE and DOE contractors from the Office of Scientific and Technical Information

P.O. Box 62, Oak Ridge, TN 37831

Prices available from (615) 576-8401, FTS 626-8401

Available to the public from the

National Technical Information Service

U.S. Department of Commerce

5285 Port Royal Rd.

Springfield, VA 22161 


\section{Final Report on LDRD Project "Proliferation-Resistant Fuel Cycles"}

Manuscript Date: Feb 1999

Prepared by

Neil W. Brown

James A. Hassberger

Lawrence Livermore National Laboratory

7000 East Avenue

Livermore, CA 94550

\section{FESSP}

Fission Energy and Systems Safety Program 


\section{Introduction}

This report provides a summary of LDRD work completed during 1997 and 1998 to develop the ideas and concepts that lead to the Secure, Transportable, Autonomous Reactor (STAR) program proposals to the DOE Nuclear Energy Research Initiative (NERI). The STAR program consists of a team of three national laboratories (LLNL, ANL, and LANL), three universities, (UC Berkeley, TAMU, and MIT) and the Westinghouse Research Center. Based on the LLNL work and their own efforts on related work this team prepared and integrated a package of twelve proposals that will carry the LDRD work outlined here into the next phase of development.

Energy demand in developing countries, particularly in Asia, is increasing rapidly to support growing populations and economies. These trends are projected to continue well into the next century. This demand will be met by a combination of fossil, renewable, and nuclear sources. However, the current mix of these energy sources does not, and cannot, satisfy all demands for new energy. Fossil fueled sources add to the accumulation of greenhouse gases and are of limited supply in many areas. Renewables, including hydro, are in limited supply, or are at an insufficient level of technical readiness to play a major role in meeting energy demands. Today's nuclear systems are too large and expensive for many areas, especially those lacking the necessary institutional infrastructure, expertise, capital or large established power grid. A small nuclear power system could provide a credible solution for meeting the growing energy demands of many regions.

U.S. foreign policy on nuclear issues is dominated by proliferation and nuclear safety concerns. Recent events in India and Pakistan have served to refocus world attention on the threat of proliferation. We are proposing to develop a new nuclear system that meets stringent requirements for a high degree of safety and proliferation resistance, and also deals directly with the related nuclear waste and spent fuel management issues.

Development of a small, modular nuclear power system offers promise as a viable alternative to either the capital intensive large nuclear systems or the environmentally problematic fossil fuel systems. Our vision is to develop a system featuring unique design elements that overcome many of the barriers to implementation of nuclear power systems in many parts of the world. Elimination of on-site refueling through a combination of long-life cores and small systems with replaceable modules reduces proliferation concerns, especially those related to spent fuel storage. Small size, transportability, modularity and the requirement for a high degree of autonomously safe operation reduce infrastructure and construction requirements of the host country, and contribute significant reductions in initial capital and operating costs. Small unit power levels make the system appropriate in areas lacking the large electrical grids normally associated with today's large nuclear systems.

A recent survey completed by the International Atomic Energy Agency (IAEA)[1] not only confirmed the need for such systems, but projected that by the year 2015, developing countries will need 70-80 small and medium-sized reactor systems. Currently, several countries are developing small reactors for this potential commercial market. For example, South Korea has been developing a concept known as SMART; Argentina has been developing a concept known as CAREM. Both systems are based on downsizing today's large light-water reactor technology to make it suitable for small power levels. China is developing a small, high-temperature gas-cooled reactor for seawater desalination and process heat. Russia is proposing several small reactor systems based on marine propulsion experience for use in developing countries, as well as remote regions of Russia. The efforts of these countries tend to focus on the development of the reactor without integrated considerations of the overall fuel cycle, proliferation, or waste issues. 


\section{Application and Systems Approach}

The system being proposed is targeted for developing regions such as South East Asia, Sub-Saharan Africa and South and Central America. There are countries within these regions with high population growth with goals to raise the standard of living. The electric power grids in some of these areas are minimal. In addition, because of geographical isolation or lack of indigenous alternatives, nuclear power may be a viable alternative. Several countries (Russia, South Korea, Argentina, China) are developing concepts for small systems that could be used in these areas.

Projected population growth for these countries will be well over 250 million by 2025 . For their standard of living to improve to half the average of the developed countries, they will need approximately $1 \mathrm{kw}$ of new generating capacity per person. This means that they will need approximately 250 Gwe new capacity, the equivalent of $2501000-\mathrm{MW}$ plants, or 2,500 100-MW plants. Continued growth in population and standard of living will double this estimate by 2050. Much of this capacity will be met with conventional technologies, including large nuclear systems. Even with large systems in place, the IAEA estimates that 70-80 small and medium-sized reactor systems will be required by 2015 . With even greater growth anticipated beyond 2015, the potential outlook for such systems is optimistic, and could require production rates on the order of 10 or more plants per year.

Successful development of a small reactor system requires a comprehensive systems approach that considers all aspects of manufacturing, transportation, operation, and ultimate disposal. This approach has been used previously in the development of a U.S. space nuclear power system, with consideration given to many diverse requirements such as no planned maintenance, highly reliable autonomous operation for a long period of time, no refueling, and ultimate disposition. While the engineering designs used for space nuclear power systems are not directly applicable to terrestrial applications, the systems approach itself offers insight into the development of a new terrestrial system suitable for developing countries. The U.S. aircraft industry also uses a systems approach in the production of new aircraft that may be suitable for small reactor modules.

Applying this system design concept to development of small nuclear power systems requires that planners consider the entire system lifecycle, including waste issues. This will lead to significant reductions in the generation of radioactive waste for the system as a whole, where, with other methods of planning, one waste minimization activity often increases wastes farther along in the system.

By considering the complete fuel cycle and impeding access to the fuel by eliminating on-site refueling, there appears to be a potential for significantly improving proliferation resistance. Such a system would simplify safeguarding the fuel and could provide a basis for development of new policies for addressing the storage and disposal issues of the fuel cycle.

\section{System Requirements}

Our principle objective is to develop a system that provides an affordable, safe and secure energy supply to countries with critical energy needs but insufficient resources to support more traditional energy solutions. The following requirements outline how this objective may be achieved. The "system concept" can be specified by key system requirements, including: 


\section{Reactor delivered pre-assembled and pre-fueled}

The nuclear reactor should be delivered to the site pre-assembled and pre-fueled. If shipping a pre-fueled reactor is precluded by safety or technical considerations, fueling must be accomplished under strict international control. Procedures to seal fuel in the vessel and eliminate further on-site access into the vessel must be established.

\section{Highly autonomous operation}

All operations, from initial startup to final shutdown, must be as autonomous as possible. Operator functions could be limited to pressing a button to start the nuclear system and performing those duties necessary to operate the power conversion or other non-nuclear systems. For the most part, an operator should only be required to monitor the status of the system. Advanced instrumentation and control technologies, coupled with the anticipated improvements in inherent reactor control mechanisms in these low-power systems, makes potential realization of such goals possible. It is recognized that this requirement is very demanding and it may become more complex as the program progresses. Significant cost savings will be associated with reductions in the number of highly trained staff required at the site.

\section{Reliance on passive safety mechanisms}

All credible failures should be safely terminated (1) by passive mechanisms in the nuclear system and (2) without the release of radioactivity to the power system site. Postulated severe accidents should be terminated without requiring emergency off-site responses. Plans for site recovery following such postulated situations should also be identified. Passive safety mechanisms are a necessary corollary to achieving the anticipated staff reductions.

\section{Limited planned maintenance}

Planned maintenance will be limited to non-nuclear, or electrical and control components easily accessed outside the reactor enclosure. Special attention must be given to eliminating instrumentation that is inherently short lived because of temperature or radiation damage.

\section{Replacement and disposal of the reactor and its contained fuel must be integrated into system design}

No on-site refueling means that at the end of a reactor core's life, the entire reactor module is replaced. This feature will help ensure that nonproliferation goals are met. A careful design will incorporate the replacement, reconditioning and disposal of expended reactor modules, including disposition of spent fuel.

These demanding goals are likely to be achievable only with systems of relatively low power compared to the 1000 MWe plants commonly used today, with the added benefit of greater security, safety, and public acceptance of the expanded use of nuclear power within developing countries.

We recognize that one of the major challenges will be to accomplish these goals with an economically viable system. Today's economic approach to nuclear power is through economies of scale. Our concept approaches the economic issue from a different perspective: we rely on the economics of mass production, coupled with cost savings achieved from dramatically reduced on-site installation, operation and decommissioning costs, reduced site infrastructure requirements, and simplified "type" licensing to overcome the loss of economies of scale. 
While many of these goals have, in principle, been met by space power systems, practical terrestrial systems that might meet this challenge will be orders of magnitudes larger than space systems, but may need to be one to two orders of magnitude smaller than the current LWRs. Even so, these requirements-while challenging - are not impossible; other complex systems such as a modern gas turbine or combined cycle plants meet many of them, including standardized factory fabrication, simple installation and startup, and highly automated operation.

LLNL has submitted a proposal to DOE to develop this system concepts in greater detail while also coordinating the work of the other STAR program participants. This project includes development of the methods for selecting of the preferred systems for further development. These methods will be similar to the model developed by the LDRD program and discussed in Section 13.

\section{Safety Concept}

Two very demanding safety requirements have been identified. First, all credible accidents (those considered to be within the design basis) should be safely terminated by passive mechanisms in the nuclear system. By "safely terminated" we mean not only that the consequences of such events be limited to the site, but such events must not result in life-limiting damage to the systems or radiological consequences to the on-site staff. Second, postulated severe accidents (those beyond the design basis) must be terminated without requiring emergency off-site responses. These postulated events should be consistent with known physical principles, and include operational failures coupled with postulated failures of protective features and equipment. An approach to recover from such postulated events, one that permits ultimate recovery of the site, should also be identified. That is, bounding accidents should not result in loss of the use of the site due to contamination. These two requirements are key to achieving the operational and design simplifications desired in the small nuclear system.

The small unit size and low unit cost of this approach presents a unique opportunity to perform a much broader range of safety verification testing than is afforded by conventional nuclear designs. This level of testing would provide a full-scale demonstration of the ability of the design to achieve the required safety envelope. Certification of the design by testing, including severe accident testing, would contribute to broad acceptance of the system in developing countries. Such an approach also supports licensing certification by test as once proposed to the NRC[2].

Safety certification of the design would be completed by the supplier, similar to procedures with commercial aircraft. Licensing the use of a factory-fabricated standard design in many different countries would then be similar to approving the use of certified aircraft. The regulatory burden on the user country would be substantially reduced.

Reliance on a high degree of autonomous operation, achieved through a combination of passive, inherent physical responses and advanced control systems, minimizes the potential for human error initiating or exacerbating off-normal events or accidents. It also reduces the training and regulatory burden on the user country. Far fewer nuclear specialists are necessary to approve and operate such systems. Similarly, eliminating the need for on-site refueling and minimizing on-site maintenance further reduces the need for a supporting infrastructure in the host country; such maintenance services may be handled by a single supplier service organization consisting of very highly trained and skilled professionals who would provide essentially all repair and maintenance functions for the entire fleet of these standardized facilities. 


\section{Operational Concept}

The infrastructure necessary to support conventional nuclear power development is very expensive, and beyond the resources of most developing countries. One of the primary goals of the proposed approach is to reduce the need for such an infrastructure. The system requirements of highly autonomous operation, simplified and minimized system maintenance, and elimination of all on-site refueling all significantly contribute to this goal.

To some extent, the complex nature of today's large-scale nuclear energy systems is a result of the many support and safety systems, often redundant, needed to ensure the safety of these very large, high-power systems. Many of these systems can be reduced or eliminated with smaller systems, where natural forces (such as natural circulation flow) are sufficiently strong to satisfy many safety and operational criteria. A more aggressive approach to automated operations is being proposed to support both large reductions of on-site staff and the technological infrastructure necessary to support operation, maintenance, and regulation. If the very high levels of reliability and simplicity of operations can be achieved, it may be possible to reduce the nuclear staff to a couple of people per shift in the main control center and a minimal electrical maintenance staff.

Nuclear instrumentation and control systems present a greater challenge. Even though it may be possible to develop a system that is inherently controlled by temperature for all normal operations, it appears that it will always be necessary to include control devices and instrumentation in the nuclear system to adequately control and monitor startup from cold shutdown, total shutdown, and possibly to compensate for fuel burnup. Design configurations that reduce the number and complexity of these instrumentation and control systems and components need to be developed.

Typically, the conventional power conversion components of a plant include dynamic machinery and numerous active control mechanisms. It will be nearly impossible to avoid planned periodic maintenance on this equipment. Even though it might be desirable to simplify and reduce the staff and infrastructure needed for this portion of the plant, the technical expertise and infrastructure required for effective maintenance and operation of these systems could be shared with that needed by other, more conventional power-generating systems the developing country will also have. Depending on the specific configuration of the system, however, there may be a cost or operational benefit that may demand supplier servicing of selected components within the power conversion portion of the plant.

\section{Manufacturing}

The importance of a totally new approach to manufacturing of the small reactors, not just modularization, cannot be over-emphasized. The concept of "designed-in manufacturability" can result in significant cost savings, particularly when amortized over a number of systems. The goal of producing a system that can be easily transported and installed can also contribute to manufacturability, as this goal leads directly to components having more "reasonable" size and mass than most of today's large nuclear power systems.

An aggressive approach to factory assembly of the plant and shipment of modules that can be quickly installed at the site will be necessary to keep costs within an acceptable range. The factory production line will need to be designed as an integral part of the product—similar to the approach taken by Boeing Airplane Company to produce their 777 model. 
The plant design would be based on production of many hundreds of essentially identical modules. Ideally, three or four major assemblies would be fabricated, quality inspected, and tested prior to shipment. With exception of the nuclear assembly and its auxiliary systems and components, these types of major production assemblies have been demonstrated in the large diesel and combined cycle plants operating under much the same technological complexity as the proposed nuclear plant.

Simplification of the system design coupled with factory manufacturing of standard modules may make it possible to challenge the economy of scale with the economy of mass production. As discussed later, it will be necessary to identify a large stable market to support this approach.

\section{Delivery and Installation Concepts}

Transportation and installation of barge- or ship-mounted small nuclear power systems is clearly feasible. Designs for barge-mounted "conventional" nuclear systems was near reality in the early 1970s, and even today, ship-mounted small reactor concepts are being proposed.

However, it is also desirable develop a system concept that is also amenable to land-based siting, including the need to transport the modules over land. This desire will place additional constraints on the size and mass of the individual modules making up a full system, especially when one considers that supporting transportation infrastructures in the developing countries (roads, railways, etc.) may be substandard or even non-existent. These considerations strongly suggest that design of special transport and handling equipment and procedures be integrated into the overall system design.

While it is likely that barge- or ship-mounted systems can be optimized at larger powers than their landbased cousins, we believe the advantages provided by mass production of very standardized units will eliminate any minor cost advantage a larger system might enjoy for barge-mounted applications.

The transport systems for removing the spent reactor modules present the greatest challenge. The problem of shipping a highly radioactive component either on land or by sea must be addressed, and associated environmental concerns will influence how the nuclear system is designed. For example, capability for recovery of a sunk shipment from the ocean bottom may be a requirement, and could have a strong influence on the nuclear module designs, even for those installed in barges or submersibles. The possible need for additional shielding, especially for overland transportation, could have an impact on the size of the nuclear module originally installed and could cause it to be quite small.

Another important requirement, related to the removal transportation, is the time period permitted between final shutdown and required removal. Because of the intensity of radioactivity and decay heat in the nuclear module immediately following shutdown, it would be preferable to leave the shutdown module in place for many months. While potentially unavoidable, such a post-shutdown delay would likely complicate replacement of the reactor module, particularly for sites with limited real estate. Although there may be a slight reduction in proliferation risk by removing the spent nuclear module soon after shutdown (as opposed to later), we believe that the difficulty associated with removing or accessing a spent reactor module to be a sufficient deterrent. Rapid removal/replacement of a spent reactor module might be accomplished sooner with the barge- or ship-based systems, but unless the installation allows separation and replacement of the nuclear system, it would mean a significant investment in unused power conversion equipment during transport or refurbishment. This may not be a great penalty if the on-station time for the system is tens of years. 
These and many other broad system issues will be the topics of the trade studies necessary to identify the preferred system. It is clear that manufacturing, delivery, and installation will have an important impact on size selection of the reactor system; the size may vary depending on the system technology.

\section{Recycling and Waste Disposal}

One of the important aspects of our systems approach is the integration of waste disposition and component recycling into the design of the overall system, including materials selection and mechanical design. It is our intent that the nuclear reactor module or the entire plant (a possibility in the case of barge-mounted systems), be shipped to an internationally monitored site for refurbishment of useable components, recycling of highly valued materials, and the preparation of waste materials for permanent disposal.

The characteristics of the "refurbishing" site and its facilities must also be integrated into the overall design, and will take into account spent fuel processing, waste treatment, and disposition of other materials and components. The extent to which other equipment is refurbished may also influence the character of the site. A barge-mounted system might be entirely refurbished; therefore, the site design would need to consider this entire refurbishment activity.

One of the more difficult issues associated with recycling and waste disposal is not a technical issue; rather, it is a political and institutional issue of how to deal with wastes, especially nuclear waste, resulting from operations in a foreign country. The U.S., and most other countries, have restrictions on the acceptance of nuclear waste from other countries. It is possible that new national and international policies, treaties, and laws may be necessary to gain all the advantages that a centralized approach might afford.

\section{System Safeguards}

Nonproliferation safeguards will be part of the proposed system to provide (1) assurance that facilities and materials are not used for illicit purposes, and (2) timely warning of an event taking, or having taken place. The proliferation risk associated with a nuclear system derives from the following four issues:

1. attractiveness of fissile materials,

2. accessibility of the materials,

3. utility of the facility for illicit purposes (for example, irradiation of fertile materials), and

4. size and character of the infrastructure needed to support the nuclear system.

Traditional large-scale nuclear power systems are quite proliferation-resistant. The fresh LEU fuel is of too low enrichment to be directly used in a weapon. The reactors are ill-suited for illicit irradiation and production of weapons material. Plutonium in spent fuel has poor isotopics for weapons applications, and is inherently protected by the significant radiation field arising from the fission product inventory. Even so, safeguards of LWR plants are needed because none of these barriers to proliferation risk is, by itself, completely effective. Diverted fresh fuel could be used to reduce the enrichment effort, given appropriate facilities. Fertile materials could, with difficulty, be irradiated in LWRs. The radiation barrier inherent to spent fuel decays with time, and plutonium from LWR spent fuel is considered a weapons-useable material, even if not ideal. 
The elimination of on-site refueling directly attacks the two greatest proliferation risks of the traditional power reactor: accessibility of materials and use of the facility for illicit purposes. Elimination of on-site refueling removes easy access to both fresh and spent fuel from the reactor site. Fissile material is found only inside the reactor, where it is protected by both limitations of physical access and a very intense inherent radiation barrier. The only period where fissile materials might be considered at risk is during transportation and set up, and during early operation where the fission product buildup is limited. Access to fissile materials and use of the reactor for illicit irradiation is further complicated by the lack of physical features and infrastructure to open the reactor vessel.

In addition to the direct reduction of proliferation risk resulting from the elimination of on-site refueling, the need and complexity of on-site surveillance can also be reduced. With the absence of on-site fresh or spent fuel storage, the need for active and/or periodic monitoring of fuel stores is eliminated. The very lack of a refueling infrastructure implies that the time necessary for opening the reactor vessel to gain access to fissile materials would be so long that the very act of shutting the reactor down may serve as the primary alert indicator. This offers potential for simplified safeguards and security that might only require monitoring to ensure the reactor is indeed operating. This could even be accomplished or augmented remotely, perhaps using satellite platforms to monitor the IR signature of the facility.

The high degree of automation desired for these systems offers three additional safeguards. First, such autonomous operation offers opportunities for remote monitoring and diagnostics that may be exploitable to assist safeguards monitoring. Second, such design offers the potential for reductions in system transients and resulting shut-downs. In such an environment, any off-normal event becomes a potential safeguards alarm. Finally, the combination of autonomous operation and elimination of on-site refueling reduces the infrastructure, including personnel, available to support illicit activities.

\section{Technology Options}

This section summarizes a preliminary assessment of the design and technological approaches that might be taken to achieve the requirements. The discussion is based on a preliminary assessment of the strengths and weaknesses each technology offers in meeting the requirements, and a cursory look at how these strengths and weaknesses might be exploited or mitigated. This assessment is only intended to provide an approximate prioritization of the concepts; each concept will be reviewed in greater detail as part of the overall program. The technologies are addressed in their current order of preference, based on their likelihood of meeting the no on-site refueling requirement with practical limits on development cost and schedules.

\section{Liquid Metal Cooled Systems}

Liquid metal cooled reactors (LMR) have been under development for more than 40 years, and several have been built and operated on commercial power grids. Sodium has been generally used as the coolant in these systems, and experience with this technology has been mixed. Sodium leaks have been the most notable technical issue, and the fact that sodium is very chemically reactive with air and water has contributed to most of the concerns about LMRs. The technology is clearly still developmental even though there is considerable valuable experience. 
Concepts based on fast LMRs have high internal conversion of fertile to fissile material and therefore have the potential for long core life without initially high reactivity that requires some form of poison compensation. LLNL and the University of California have developed some variations on the Japanese $4 \mathrm{~S}$ concept that could extend its neutronic life to more than 15 years $[3,4,5,6]$. Although there are unanswered concerns about the clad and structural damage from large neutron irradiation, the results of preliminary work are encouraging.

Fuel systems for LMRs are well developed. Oxide, carbide, nitride or metal fuel have been demonstrated and provide many options for addressing the long life requirement for the fuel. Metal fuels, in particular, offer promise of improved safety characteristics.

Liquid, metal-cooled systems operate at low pressure and have very large thermal margins relative to their boiling temperature. There is negligible thermal energy stored in the coolant available for release in the event of a leak or accident. This translates to the potential for compact system designs, including containment. In addition, the large thermal expansion coefficients of liquid metal coolants inherently support good thermal characteristics for natural circulation cooling and provide very favorable passive safety characteristics.

As mentioned above, the sodium coolant used by most LMR developers has created some safety concerns because of its chemical reactivity with air and water. Lead, lead-bismuth or other alloys of lead appear to eliminate these concerns because the chemical reactivity of this coolant with air and water is very low. The Russians have extensive experience with this coolant and, when combined with the Japanese 4S configuration, it conceptually is a very attractive system. Several major issues must be addressed, however, including what appears to be the most important: materials corrosion. This is a serious issue, and although the Russians have had success in this area, long-term materials compatibility must yet be established.

Extensive development and demonstration work, beyond that required for a small LWR-based concept, may be required. These reactors also require fuel that is enriched to nearly $20 \%$ and therefore fuel recycling may be necessary to achieve economic performance. Because of the developmental uncertainties and the possible need to include fuel recycling in the system, the cost of implementing a system design based on liquid metal coolant is uncertain.

ANL has submitted a proposal to DOE, STAR-LM, that will develop an LMR concept to address the STAR systems requirements that will be developed under the LLNL STAR system proposal.

\section{Gas-cooled Systems}

Gas-cooled reactors, although not extensively used for electric power generation, have continued to be used and receive developmental attention. There have been many years of successful power operation on the power grid in England. Helium has become the coolant of choice in the high-temperature versions of this technology. Recently, development work has focused on modular reactors coupled to gas turbines to improve both economics and the passive safety characteristics. Considerable effort has been invested in development of graphite-coated fuel particles that are imbedded in a graphite matrix. However, there is also considerable experience with cermet fuels which have fuel particles imbedded in a metal matrix. This later technology has not received much commercial attention, although extensive development is completed for application in aircraft and space systems. 
There is some continuing interest in gas-cooled reactors in South Africa, China, and Russia. ESKOM, the South African state-operated utility, is interested in a high-temperature, gas-cooled reactor combined with a direct cycle gas turbine for powering rural areas that are currently without electricity. They have developed a preliminary design for a system based on the pebble bed reactors developed in Germany. General Atomic and Russia, in cooperation with others, have also completed a study on design of a gascooled gas turbine plant for use in Russia. China has operated a $5 \mathrm{MW}_{\mathrm{t}}$ gas-cooled reactor and has plans for construction of a $200 \mathrm{MW}_{\mathrm{t}}$ which is intended for process heat applications.

Since gas-cooled reactors are predominantly thermal spectrum reactors, the challenge will be to develop a concept for extending core life. De-rating the fuel and operating the reactor at lower power densities than under optimum operating conditions is one possibility. This could have an unfavorable impact on economics. Thorium fuel cycles applied to these types of reactors could be used to contribute to increased core lifetime. However, on-line refueling - in which pebbles are added and removed on a frequent basis - has been the emphasis in the pebble bed reactors. Some conceptual designs for pebble bed reactors specify that the reactor vessel is only partially filled at the start of life. Fuel is gradually added, thus extending reactor life. Consideration could be given to hardening the spectrum and improving the internal conversion, possibly even using cermet fuel in a fast spectrum reactor.

The modular designs studied in recent years have very favorable passive safety characteristics. Both the Russian and ESKOM designs incorporate robust passive safety capability. Although the systems run at high pressure, there is little energy stored in the single phase coolant and the thermal margins in the fuel are very large. Thus, a loss of coolant during an accident may be accommodated passively. However, containment design continues to be a question and may add to system size and complexity.

The direct cycle gas turbine is the most attractive configuration for the gas technology. Inclusion of steam generators contributes complexity and decreases efficiency and reliability. Even though there has been no operational experience with a direct cycle gas turbine HTGR (and therefore development costs and risks are high), once developed it is expected to be very economical. This is a viable candidate that has seen considerable progress in the development phase but awaits demonstration.

LANL has submitted a proposal to DOE, STAR-G, that will develop an HTGR concept to address the STAR systems requirements that will be developed under the LLNL STAR system proposal.

\section{Light Water Cooled Systems}

The LWR is the most highly developed and deployed reactor and fuel cycle system in the world. Many small versions have been designed and even deployed, although most have been limited to submarine versions and other special purposes where economics has been a secondary requirement. The possibility of adapting various highly developed marine systems to small electric generator designs is being seriously considered as a viable option.

The main challenge facing this technology will be to extend the refueling interval much beyond two years while maintaining the inherent safety objectives. Power de-rating, similar to the gas reactor, can extend core life at the expense of increases in power cost and physical size. There are efforts underway to extend fuel life to three years, but to make this technology viable, it is likely that fuel life will need to be extended further. Long-term autonomous control may also be a challenge, partly due to reactivity changes over the life of the plant and other technical issues, such as the need to maintain water chemistry and pressure control. 
The small units can be made simpler and include large margins to safety. Natural circulation cooling at full power is possible. However, because of the large amount of stored energy in the coolant, a pressureretaining containment is necessary to meet the safety objectives. It is also likely that active safety components such as isolation valves may be required.

LWR technology is the most developed technology and therefore may have very low development costs. Yet the significant development needed to achieve long fuel lifetimes required here may offset the economics afforded by the mature underlying technology base. Additionally, the high system pressure and significant thermal energy stored in the coolant complicates safety and containment design, and is expected to increase system size, mass, and cost.

Westinghouse Science \&Technology Center has submitted a proposal to DOE, STAR-LW, that will develop an LWR concept to address the STAR systems requirements that will be developed under the LLNL STAR system proposal.

\section{Molten Salt Systems}

One molten-salt reactor system has been constructed, and although its experimental operations were successful, there have been no others. The interest has been largely academic, but conceptual designs of commercial plants have been developed. This technology would require the largest development and demonstration program, and with no licensing experience, could prove to be a difficult option to implement.

One of the major concerns about this technology, besides the limited technology base, is the lack of materials with demonstrated long-term compatibility. Long-life operation will require on-line chemistry control and processing of the molten-salt fuel, and although demonstrated at the laboratory level, such processing remains a development issue.

Interest in the molten salt system is based on the promise of long reactor life through automated fuel processing and management. Automated additions of fuel and removal of the fission products, if possible, could eliminate fuel life as a limiting factor to system life. Such automation is clearly a major challenge.

Because the reactor can be designed with very little excess reactivity in the core and the molten salt has very good heat transport characteristics, the potential for achieving passive safety objectives also exists. The fact that (1) the molten-salt reactor is a low pressure system, and (2) the coolant is very chemically stable and does not react with air or water also support the passive safety characteristics of this concept.

However, the fact that the fuel is both mobile and unclad raises serious concerns about fuel leakage and containment and control of the gaseous fission products. These concerns will impact the designs of containment and fuel chemistry management systems, and may require significant developmental efforts to demonstrate.

This technology is clearly very speculative and would likely require the most development and demonstration. The cost and schedule for implementing a concept based on this technology may also be the most demanding. With innovative use of automation, however, it may be possible to realize a design concept that best addresses functional requirements.

LLNL has submitted a proposal to DOE, STAR-MS, that will develop an MSR concept to address the STAR systems requirements that will be developed under the LLNL STAR system proposal. 


\section{Other Technologies}

We have briefly reviewed other technologies, such as heavy water reactors, but have not identified any with sufficient merit to warrant consideration. The CANDU-HWR is well developed but uses on-line refueling which is contrary to the objective of excluding on-site refueling.

There are LWR and LMR advanced fuel-cycle schemes being investigated with potential to improve the proliferation resistance of current reactors. However, they usually require extensive fuel shuffling or fuel modifications to make the fuel less suitable for weapons application. These approaches may be found suitable for large reactors, but they do not appear compatible with small reactors that have a requirement for no on-site refueling.

\section{R\&D Issues}

The proposed program for designing a new, proliferation-resistant reactor is based on systematic, requirements-driven evaluations. That is, we believe it imperative to develop a consistent, well thought set of performance, design, and operational criteria that truly reflect the goals of the program rather than to make marginal improvements to existing systems. Even though the latter approach has clear short-term advantages in terms of development effort, cost, and schedule, we believe the marginal improvements in both proliferation resistance and fundamental safety are insufficient to support broad institutional acceptance of such designs.

While it is possible that systems based on existing technologies may be conceived that meet the objectives, it is likely that an extensive R\&D effort will be required. Without clearly defined concepts, we can only outline the general scope of such a program. In fact, the development of system concepts is the first major program objective.

Clearly, systems designed for long-term operation without refueling will place new demands on fuels and in-core materials compatibility and performance, and will demand improved analytic techniques, including nuclear analysis and structural performance methods. Desirability of transportable designs may require new methods of manufacturing, transport, and installation. New approaches to siting and design certification, perhaps through new international institutions, could facilitate a broader acceptance of such systems and installations, and minimize infrastructure development in the host country. Implementation of highly reliable automated controls that rely on a minimum of instrument signals will need to be developed. 


\section{Approaches to Financing}

Financing the initial research necessary to realize a small reactor concept for developing countries is under discussion with the U.S. Department of Energy (DOE). We are seeking to recruit international advisors early in the program, and build international participation as the program matures and funding increases. The program being proposed would include two major phases lasting approximately 12 years. The first five-year phase would lead to a conceptual design of a preferred and backup system. The first phase would be financed by the participating governments. During the second phase, a prototype would be developed for certification testing. During this phase, it is expected that support for certification testing would come from major governments, while support for establishing the production facilities would come from commercial participants. These facilities would be used to produce the prototype as well as the subsequent production models. It is envisioned that the program would shift from largely governmentsupported laboratory research into a partnership with industry that would then lead to industry-operated facilities subject to international monitoring. These facilities would include factories and production lines used to produce standard assemblies suitable for use at many sites. 


\section{Evaluation and Down Selection}

One of the objectives of the project was to develop a process for evaluating the relative merits of the alternative systems and to use these to establish a metric to support selection of a preferred system for further development. The work on this task progressed only to a preliminary level. A decision model was constructed using the commercial computer code Logical Decisions was developed but not applied to making the selection. Prior to this work being completed, it was recognized that DOE was going to initiate the NERI program that would provide an ideal forum for completing the evaluations and down selection to a preferred concept.

The attributes and decision tree that was developed are shown in Figures 1,2 and 3. The figures show the set of attributes that were selected. There are four top goals identified in Figure 1; Proliferation

Resistance, Cost, Environmental Safety and Health (ES\&H) and Institutional. In this model the attributes applicable to proliferation were detailed to a much greater extent than inputs to the other three top goals because at the time it was thought that most of the effort would be given to characterizing these parameters. Figure 2 shows the detailed input to the Cost, ES\&H and Institutional goals while Figure 3 shows the details for the theft and diversion elements of the proliferation goal.

The methods for identifying and selecting the weights for the proliferation attributes were based on the LLNL experience with developing a similar decision analysis model to support selecting the preferred mode for disposing of the excess weapons plutonium [8]. These will be reviewed as part of the proposed STAR program if funded under NERI. Arbitrary trial values were selected and input to the Logical Decisions computer code to test that the model could be processed by the code. These tests were successful but the results meaningless because of the minimal attention that was given to the selection of inputs. The model should provide a good starting point for the future work. 


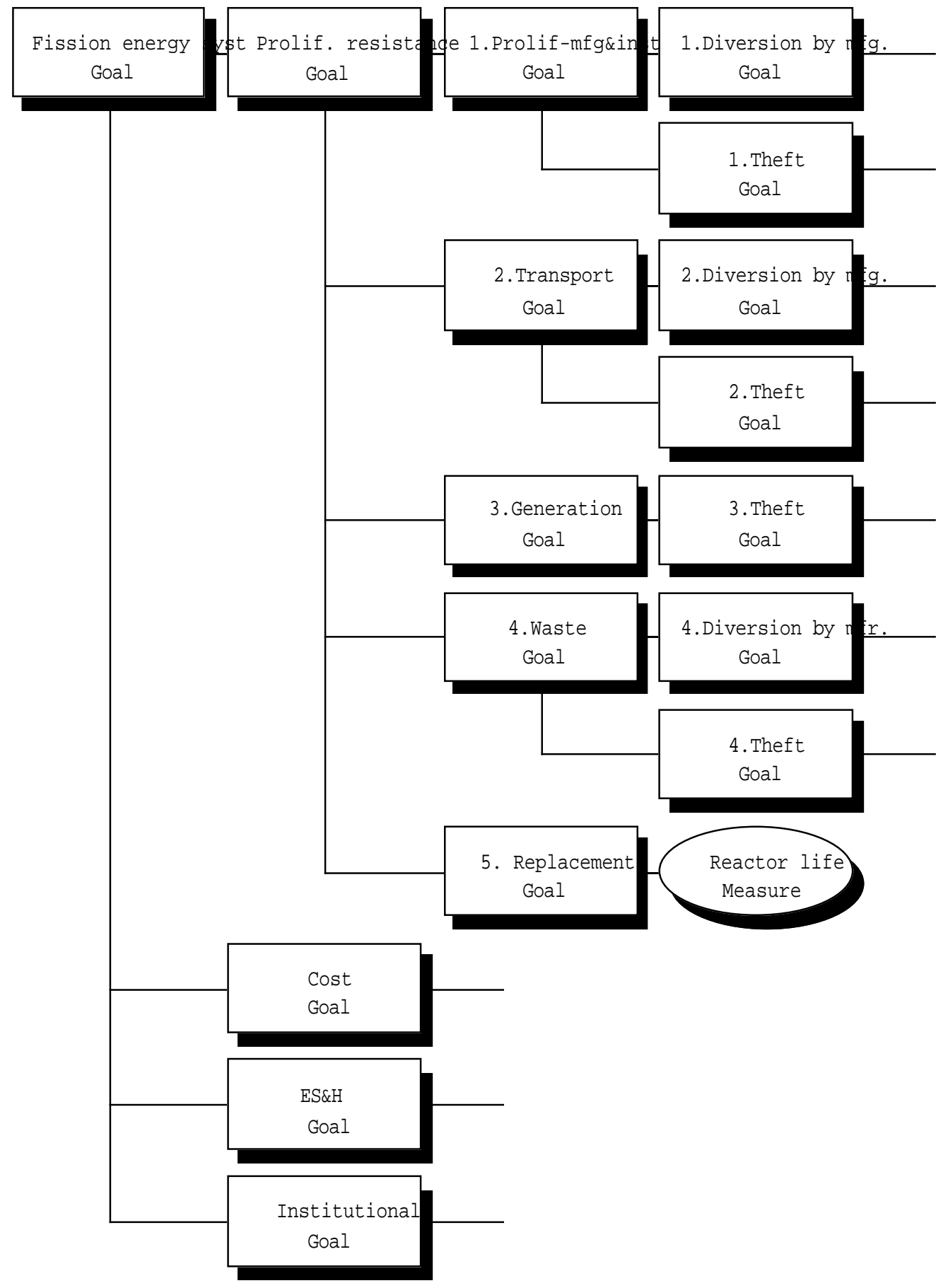

Figure 1 Multi-attribute Decision Tree for Selecting Preferred Concept 


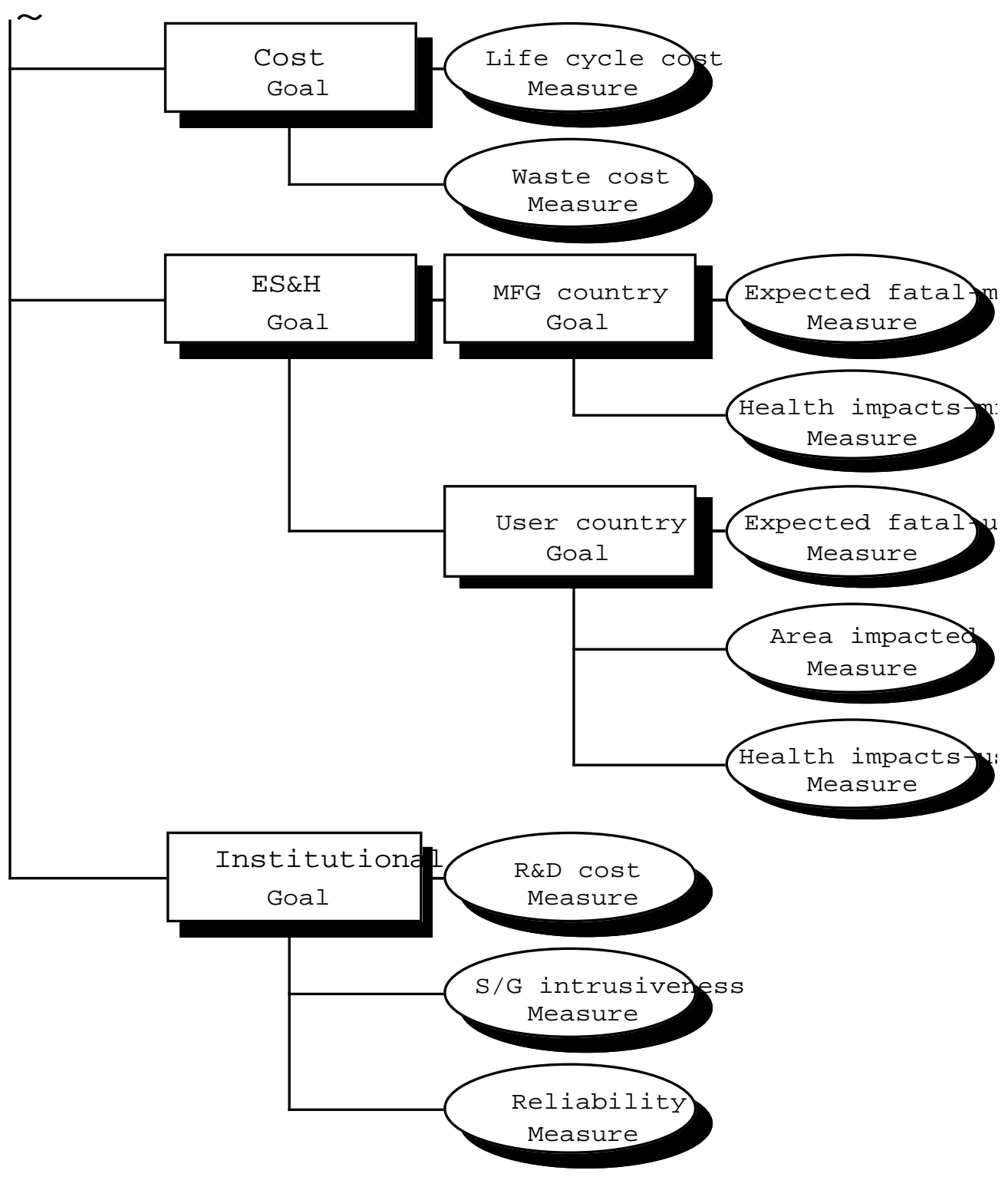

Figure 2 Multi-attribute Decision Tree for Selecting Preferred Concept (continued) 


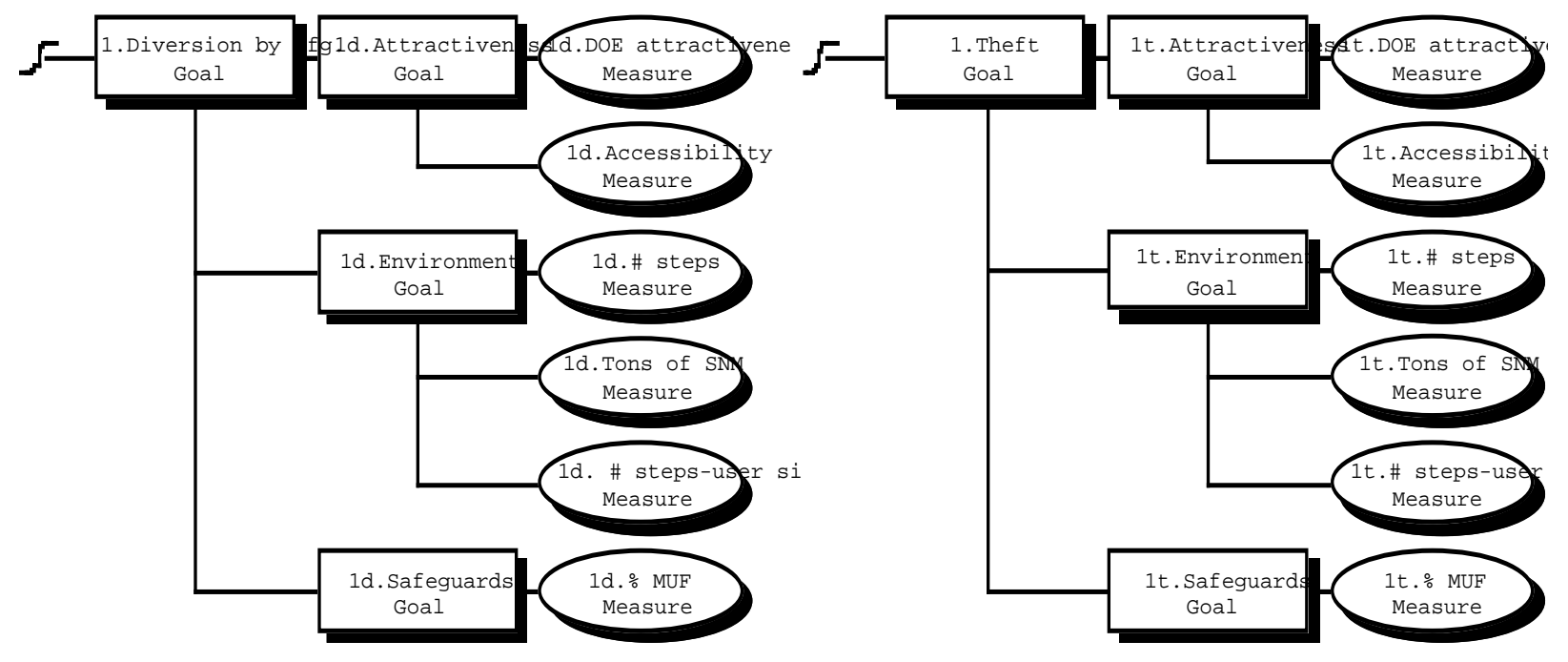

Figure 3 Multi-attribute Decision Tree for Selecting Preferred Concept (continued) 


\section{References}

1. "Introduction of Small and Medium Reactors in Developing Countries," Proceedings of two Advisory Group meetings held in Rabat, Morocco, 23-27 October 1995 and Tunis, Tunisia, 3-6 September 1996.

2. N. W. Brown et al. "An Innovative Approach to Nuclear Reactor Design Certification," ASME 87-JPGC-NE-3, 1987.

3. N. W. Brown et al. "Proliferation Resistant Fission Energy Systems," Proceedings of the Global-97: International Conference on Future Nuclear Systems, Yokohama, Japan, October 5-10, 1997, pp. 879-884.

4. S. Hattori and N. Handa. "Use of Super-Safe, Small and Simple LMRs to Create Green Belts in Decertification Area," Transactions of the American Nuclear Society, 60:437 (1989).

5. S. Kasai Aoki and S. Hattori. "Design of Small and Simple LMR Cores for Power Generation in Remote Communities," Proceedings of the 3rd ASME-JSME International Conference on Nuclear Engineering, ICONE-3, Tokyo, Japan, October 1995.

6. Ehud Greenspan et al. "Compact Long-Life Reactors for Developing Countries," International Conference on Emerging Nuclear Energy Systems, Tel Aviv, Israel, June 1998.

7. Logical Decisions for Windows, Version 4.1, Logical Decisions, Golden Colorado, February, 1997

8. J. S. Dyer, T. J. Edmunds, J. C. Butler, J. Jia, "Evaluation of the Alternatives for the Disposition of Surplus Weapons-usable Plutonium (ANCRP-1997-1), April 1997. 